\title{
Catalyzing Sustainable Transport Innovation through Policy Support and Monitoring: The Case of TRIMIS and the European Green Deal
}

\author{
Anastasios Tsakalidis*(D), Mitchell van Balen, Konstantinos Gkoumas and Ferenc Pekar \\ European Commission, Joint Research Centre, 21027 Ispra, Italy; mitchell.van-balen@ec.europa.eu (M.v.B.); \\ konstantinos.gkoumas@ec.europa.eu (K.G.); ferenc.pekar@ec.europa.eu (F.P.) \\ * Correspondence: anastasios.tsakalidis@ec.europa.eu; Tel.: +39-0332-785907
}

Received: 4 February 2020; Accepted: 11 April 2020; Published: 15 April 2020

\begin{abstract}
Transport contributes significantly to economic growth and higher quality of life, but its associated externalities have an environmental, economic and social impact and are the main impetus to support innovation towards sustainable transport. The European Commission's Communication on a European Green Deal sets out the objective of achieving climate neutrality by 2050, for which transport emissions will need to be further reduced. Innovation within the transport sector gains greater prominence, with some anticipating an innovation revolution that would completely transform the sector. In this paper, the barriers that impede such a transition from happening are examined and a tool that aids policymakers and researchers with shaping transport innovation actions is presented; The Transport Research and Innovation Monitoring and Information System (TRIMIS) is an integrated transport policy-support tool with a modular design serving as an open-access information and knowledge management system. This paper provides an overview of its main features and includes a case study on transport electrification and alternative fuels, showing how monitoring efforts can aid transport research and innovation (R\&I) policymaking and governance. TRIMIS contributes to identifying evolutionary and revolutionary technologies, their funding and associated policy initiatives, so the anticipated transport revolution can be better monitored, evaluated and shaped.
\end{abstract}

Keywords: decarbonization; transport policy; transport research governance; transport technologies; capacity mapping; horizon scanning

\section{Introduction}

Transport makes significant contribution to economic growth and higher quality of life by facilitating the movement of people and goods. On the flipside, it causes externalities that have detrimental effects on the environment and public health [1-3]. These externalities are the main impetus to support innovation that makes transport greener, safer and more efficient.

Innovation in the transport sector has been historically characterized by small and incremental changes, often affected by the political and economic context, and in many cases being supported by policies and standards introduced by political and financial systems [4]. Technological advances and innovations, developed to address the often systemic nature of transport-related challenges, constitute part of a greater transport system which comprises a series of aligned elements [5].

Recently, innovation activity within the transport sector surged, often adopting new and emerging technologies and trends [6]. Innovation spillovers from fields like Information and Communication Technology and Artificial Intelligence catalyze a sectoral transformation, which could have far-reaching implications. For urban transport in particular, disruptive technologies, social change and regulatory pressures are creating disruptive innovation at industry segments (e.g., taxi service has been disrupted 
by new smartphone-enabled services), industry structure (e.g., a shift from car ownership to pay for use), as well as at social systems (e.g., rise in self-employment) [7]. Non-technological transport innovations (e.g., sustainable urban mobility plans-SUMPs) equally contribute towards the improvement of transport issues [8]. Furthermore, urban areas are also important in terms of catalyzing the various preventive dimensions of transport policy $[9,10]$.

It is, however, not given that a so-called transport innovation revolution will take place [11]. In part, this is related to the inherently high level of complexity of transport systems, which comprise a wide spectrum of physical and organizational elements, influencing each other in various ways [12]. Additionally, society often shows reluctance towards embracing new technologies [13]. The transport sector, falling within the 'legacy sector' categorization [14] has been showing signs of resistance towards the introduction and scale-up of innovations. Their level of acceptance relies principally on the human factor and its surrounding societal issues and interactions, including among others safety, security, sustainability and climate change [15].

Various standard adoption models have been proposed in the last decades that try to provide a more structured view on the development of the maturity of emerging technologies through their various phases, ranging from technology trigger to mainstream adoption [16]. However, unforeseen events can change existing trends and influence socio-economic cycles [17], thus, innovation adoption in general. Finally, the existing policy and industry status and stakeholder activity have not unequivocally benefited the transport innovation revolution. In this context, it is necessary to reflect on the role of political decisions in this field and the instruments that are adopted to support innovation. The role of political decisions can vary, considering that a technology may or may not require particular policy attention, for example if a technology's potential has already been identified and targeted by industry [18]. Furthermore, it is crucial, together with funding or creative thinking, for the further progress of innovation ecosystems (e.g., innovation platforms, networks) [11]. In the general policy of sustainable transport development and more specifically transport systems, a multifaceted approach to the development is important, as for example in the case of transport infrastructure [19,20].

This paper, therefore, reflects on how political decisions influence transport innovation and argues in favor of a guidance system to overcome some of the identified issues. The paper consists of the following parts: after the introduction, the next section discusses the structural characteristics of the transport sector and the impact on innovation dynamics, including a discussion on the shortcomings of current innovation policies. On the basis of this review, a comprehensive policy and monitoring system, which provides guidance to research efforts is presented as a means to catalyze the transport innovation revolution. It consists of a policy framework ('STRIA') introduced by the European Commission (EC) and its respective monitoring system ('TRIMIS') co-developed by the authors. A case study of the systems application is provided analyzing the advances of the European research and innovation (R\&I) in the fields of transport electrification and alternative fuels, two domains in direct connection with the sustainability goals of the recently published European Green Deal [21]. The paper concludes by discussing the strengths and weaknesses of policy support for transport innovation.

\section{Catalyzing Transport Innovation}

\subsection{Barriers to Innovation}

The transport sector is often critically assessed for the way externalities are addressed. For example, there is still ample need to reduce the environmental impacts of shipping and aviation, while there is also continued policy pressure on the automotive industry to cut pollutant and greenhouse gas emissions [22]. Several factors explain why externalities are not adequately resolved through transport innovation.

A first point can be linked to the role of government. Building on stakeholder theory [23,24], it can be hypothesized that governments hold multiple contradictory roles in relation to the transport sector. Governments across the world are heavily invested in their respective transport industries, both in 
manufacturing and operations. In aerospace, large aircraft manufacturers and airports are pertinent examples [25]. In shipping, governments finance shipyards, hold shares in several container liners and own ports [26]. Regarding the automotive industry, substantial government support to manufacturers during years of economic crisis as well as high levels of state ownership was observed.

While governments can push the transport sector towards a more efficient, clean and innovative future, impeding behaviors are exhibited as well. A recent example concerns discussion on new emission standards for cars in the European Union, where some Member States were accused of preventing stricter $\mathrm{CO}_{2}$ emission standards to protect the interests of national car industries and local employment [27]. Thus, it could be argued that the multiple roles of governments can impede innovative behavior. Competition dynamics are one [28]; Transport industries are generally highly competitive, so that multi-million investments to develop and implement technological solutions can threaten business continuity. Industries like container shipping and freight forwarding come to mind. In other cases, transport industries enjoy a state-imposed monopoly (i.e., national railway undertakings), which limits innovation in various ways.

A more recent development in the competitive landscape is that surge of entrants with a distinct digital focus. A few notable examples are Flexport in freight forwarding, Tesla in automotive, Amazon in logistics, or Uber in passenger transport. Furthermore, it becomes more evident that the geographical profile of transport innovations is changing. The World Intellectual Property Organization [29] notes that China drives international patent application to record numbers, including in the field of transport. The emergence of new entrants in the field of transportation and the changed geography of research are in many ways beneficial to the level of innovation in the sector. At the same time, it makes that research is increasingly fragmented, adding an additional level of complexity to the already differentiated innovation predisposition among the various transport modes (road, rail, aviation, waterborne) and sub-sectors (e.g., services, construction) [30].

Complexity is one of the main challenges in assessing modern transport systems, since they are affected by a series of technical limitations, financial and ecological constraints, and public interest, but also diverging points of view of various transport stakeholders trying to maximize their individual advantage. Consequently, the examination and evaluation of transport systems requires a multi-criteria decision-making approach [31].

This complexity can contribute to a misalignment of research actions between business, government and academia. Alignment is particularly important considering the ambitious objectives that aim for net-zero greenhouse gas emissions in a few decades (e.g., the European Green Deal's aim of achieving no net emissions of greenhouse gases in 2050) and the deployment of fully autonomous driving. Experts have tempered expectations by pointing at the substantial barriers that need to be overcome through resource-intensive research projects that require the involvement of many different organizations. Particularly, it is indicated that innovation is not purely dependent on technological progress, but on the development of successful business models and an appropriate legal and funding framework. As such, there is a strong need for a strong and coordinated policy framework and in particular, for a triple helix approach [32] in which business, government and academia make a concerted effort to push the transport sector towards decarbonization, in line with the European Green Deal's objectives [21].

Considering the above, it is concluded that there are substantial barriers in place that need to be addressed before a so-called 'transport innovation revolution' [11] will materialize. The next section expands on the various roles of political decisions in catalyzing this process and what instruments still need to be put in place.

\subsection{Public Support for Innovation}

In light of the challenges that the transport sector is confronted with, a large number of instruments are leveraged to promote innovation. Building on the framework by Hekkert et al. [33] on different innovation functions, Table 1 presents an illustrative selection of intervention types and instruments 
that are used at European level. In the EU, there is a long tradition of funding transport innovation, promoting entrepreneurial activities, developing and sharing knowledge and developing networks of researchers and organizations with the ultimate objective to transform economic sectors in line with policy objectives. For these activities, there exist well-established and long-standing procedures. The other functions have been developed over time and became more mature during the last decade or so.

Table 1. Transport Innovation System: selected activities (Composed by the authors).

\begin{tabular}{|c|c|c|c|c|}
\hline & $\begin{array}{l}\text { Innovation } \\
\text { Functions }\end{array}$ & Intervention Type & $\begin{array}{l}\text { Important } \\
\text { Instruments }\end{array}$ & Description \\
\hline 1 & $\begin{array}{l}\text { Guidance of } \\
\text { research }\end{array}$ & Committee & $\begin{array}{l}\text { Transport Program } \\
\text { Committee }\end{array}$ & $\begin{array}{l}\text { Delegates of EU Member States convene to } \\
\text { define the outlines of transport research calls } \\
\text { under research framework programs. }\end{array}$ \\
\hline 2 & $\begin{array}{l}\text { Entrepreneurial } \\
\text { activities }\end{array}$ & Research grants & Framework Programs & $\begin{array}{l}\text { Funding programs for research and } \\
\text { technological development. Includes specific } \\
\text { actions to promote entrepreneurial activity, } \\
\text { such as the Small and Medium Enterprise } \\
\text { (SME) actions. }\end{array}$ \\
\hline 3 & $\begin{array}{l}\text { Knowledge } \\
\text { development }\end{array}$ & $\begin{array}{l}\text { Research } \\
\text { grants/Information } \\
\text { portals }\end{array}$ & $\begin{array}{c}\text { Framework } \\
\text { Programs/Transport } \\
\text { Research International } \\
\text { Documentation }\end{array}$ & $\begin{array}{l}\text { In addition to Framework Programs, portals } \\
\text { exist that disseminate knowledge on recent } \\
\text { technological advances in transport (e.g., } \\
\text { Transport Research International } \\
\text { Documentation-TRID portal). }\end{array}$ \\
\hline 4 & $\begin{array}{l}\text { Knowledge } \\
\text { diffusion through } \\
\text { networks }\end{array}$ & Support networks & $\begin{array}{l}\text { Public-private } \\
\text { partnerships }\end{array}$ & $\begin{array}{c}\text { Several partnership models exist to foster } \\
\text { knowledge sharing, such as European } \\
\text { Technology Platforms and Joint } \\
\text { Undertakings. }\end{array}$ \\
\hline 5 & Market formation & Public procurement & $\begin{array}{l}\text { Innovation } \\
\text { procurement }\end{array}$ & $\begin{array}{l}\text { Special attention is given under Framework } \\
\text { Programs to promote procurement initiatives. }\end{array}$ \\
\hline 6 & $\begin{array}{l}\text { Resources } \\
\text { mobilization }\end{array}$ & Finance & $\begin{array}{l}\text { European Fund for } \\
\text { Strategic } \\
\text { Investments/Connecting } \\
\text { Europe Facility }\end{array}$ & $\begin{array}{l}\text { Financial instruments are put in place to } \\
\text { bring mature innovations to market. }\end{array}$ \\
\hline 7 & $\begin{array}{l}\text { Creation of } \\
\text { legitimacy }\end{array}$ & Legislation & $\begin{array}{l}\text { Directives and } \\
\text { regulations }\end{array}$ & $\begin{array}{l}\text { Legislative texts can foster the development } \\
\text { and adoption of technologies, for instance by } \\
\text { setting ambitious targets. }\end{array}$ \\
\hline
\end{tabular}

One example concerns how networking and knowledge sharing has been endorsed. European Institutions and industry have collaborated in so-called Joint Undertakings, in which resources are pooled, research projects are designed, and knowledge spread. Such public-private partnerships are embraced as a way to foster innovation [34].

A second case concerns financial instruments. In addition to funding research through European Research Framework Programs, the difficulties that organizations experience with bringing transport innovations to market have been acknowledged by putting in place several supporting schemes over the last decade. The Connecting Europe Facility, for example, increasingly focuses on funding innovative projects that embrace technological advancements.

A final element, which constitutes the core of this paper, is the guidance of research. For long, transport funding programs have been shaped by deliberation between (national) delegates and topical experts. There are however a few notable limitations to this approach. First, deliberation alone does not provide any framework to guide research and may be subjected to more ad-hoc considerations. As such, there is a risk that funding priorities are set without broader coordination. The next European Research Framework Program, Horizon Europe [35] aims to overcome this limitation by clustering research areas (e.g., transport belongs to the Energy, Climate and Mobility cluster) and by research and innovation missions to increase the effectiveness of funding by pursuing clearly defined targets. Another issue is that no monitoring and evaluation aspects are formally integrated in the guidance process. The subsequent issue is that when projects and programs are insufficiently assessed in terms of outcomes, no adequate measures can be taken to redirect resources if needed. A final argument is that delegates often have a specific focus, say one industry or field of technology. This makes that the 
interlinkages between innovation processes are not necessarily fully taken into account when funding decisions are being taken.

To address these points, a more comprehensive system for leveraging transport R\&I has been proposed and established by the EC to support the decarbonization of the European transport sector. Taking into consideration the previously discussed complexity in assessing modern transport systems and the existing policy framework, targeted transport R\&I monitoring efforts can aid all relevant policymaking and governance. In the light of the above, the authors co-developed an integrated transport policy-support tool with a modular design serving as an open-access information and knowledge management policy support tool that constitutes one pillar of the two-dimensional proposed system. In the section below, this system will be discussed in detail.

\section{Guidance of Research: Policy and Monitoring Frameworks}

The system presented here consists of two distinct but inseparable parts:

1. A policy framework that sets out the Needs and Objectives, called the Strategic Transport Research and Innovation Agenda (STRIA);

2. A monitoring and evaluation system to measure whether the inputs and activities create the desired effects in achieving the Needs and Objectives, called the Transport Research and Innovation Monitoring and Information System (TRIMIS).

These parts and their interaction are described in greater detail below, after which some analyses are shared that follow from the system.

\subsection{Policy Background-STRIA}

In 2016, the EC published a European strategy for low-emission mobility and a series of relevant Communications to promote clean energy innovation in Europe, underpinning a new approach to transport R\&I targeting at current and future socio-economic and environmental challenges [36-38]. In order to address those challenges technological advancement is required, and transport R\&I is an enabler within a competitive European and global environment under constant evolution. The EC has recognized this need and therefore, in 2017, the Strategic Transport Research and Innovation Agenda (STRIA) was adopted as part of the "Europe on the Move" package, which underlines the main transport R\&I areas and priorities for clean, connected and competitive mobility, complementing the 2015 Strategic Energy Technology (SET) Plan [39,40]. The priority areas with specific actions for future R\&I to decarbonize transport and mobility are outlined in seven STRIA roadmaps:

1. Cooperative, Connected and Automated Transport, supporting the development of a customer-centric, intermodal and integrated transport system aiming at greater efficiency, safety and wellbeing and environmental impacts mitigation.

2. Transport Electrification, supporting the promotion of developments carried out in the framework of the European Green Vehicle Initiative and encouraging multi-sectorial and multidisciplinary R\&I activities on new materials, advanced propulsion systems and Information and Communication Technology (ICT).

3. Vehicle Design and Manufacturing, supporting the development of successful marketable transport vehicles with shorter development times.

4. Low-emission Alternative Energy for Transport, focusing on renewable fuels production, alternative fuel infrastructures, as well as the impact of these technologies on transport systems and services covering all transport modes.

5. Network and Traffic Management Systems, supporting the development of an advanced multimodal transport system through the optimization of the entire transport network across new areas.

6. Smart Mobility and Services, supporting new and emerging technologies such as electric and autonomous vehicles, drone technology and on-demand mobility services. 
7. Transport Infrastructure, supporting the development of research and innovation, testing new methodologies and preparing the ground for future transport infrastructure policies.

The implementation, updating and further development of STRIA required the support of an effective monitoring and information mechanism that provides insights to all stakeholders involved in transport R\&I. In this context, TRIMIS has been developed at the EC Joint Research Centre (JRC) aiming to provide a holistic assessment of transport R\&I, technology trends, to create technical and socio-economic capacity maps and to publish data and analyses fully covering the European transport system.

\subsection{Implementation-TRIMIS}

TRIMIS is developed as the analytical support tool for monitoring and assessing the implementation of STRIA. Moreover, it is the EC instrument for mapping technology trends and R\&I capacities in the transport sector, and for monitoring progress against policy goals. The implementation of TRIMIS aims to cover the whole transport R\&I spectrum and meet the needs of all transport stakeholders with main focus on policymaking and governance. Figure 1 provides an overview of the potential added value of TRIMIS by user target group.
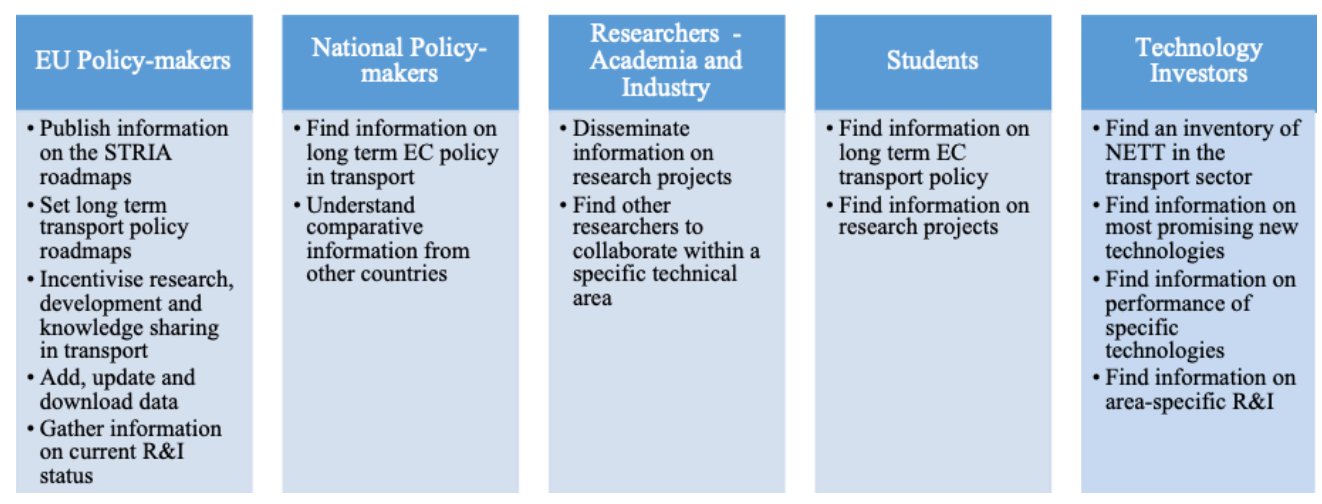

Figure 1. TRIMIS user target groups and potential added value (Adapted from [41]).

It is designed as an open-access information and knowledge management system and is intended to cover the whole spectrum of R\&I in the transport sector. Figure 2 provides an overview of TRIMIS main features and functionalities.

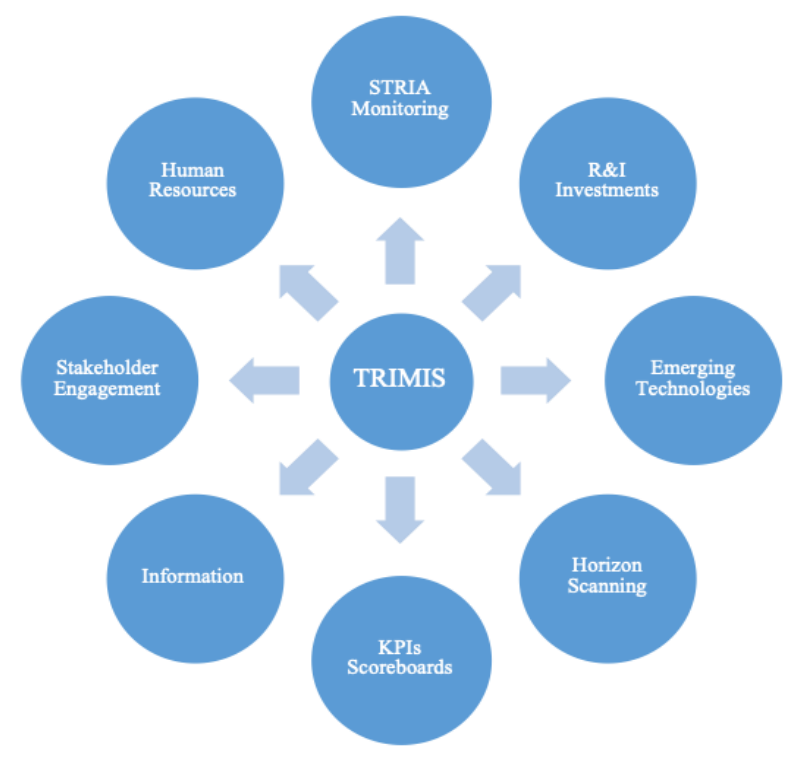

Figure 2. TRIMIS main features and functionalities [42]. 
One of its novel characteristics is that, contrary to existing transport policy-support tools, TRIMIS provides an integrated approach to bring socio-economic figures and strategic foresight together. This is achieved by providing a bidirectional monitoring and assessment of transport innovation both backward looking, through historic trend analysis, but also introducing a forward-oriented approach through the use of strategic foresight and the development of an inventory on new and emerging technologies and trends (NETT) in the transport sector. This is a step-change compared to traditional practice according to which strategically oriented policies have been based on insights gained through a sporadic assessment of the current status in various fields and the intuition of those in charge [43], a type of practice not suitable to address the contemporary levels of complexity and evolution rate of the transport sector. Figure 3 schematically presents the bidirectional monitoring and assessment approach of TRIMIS.

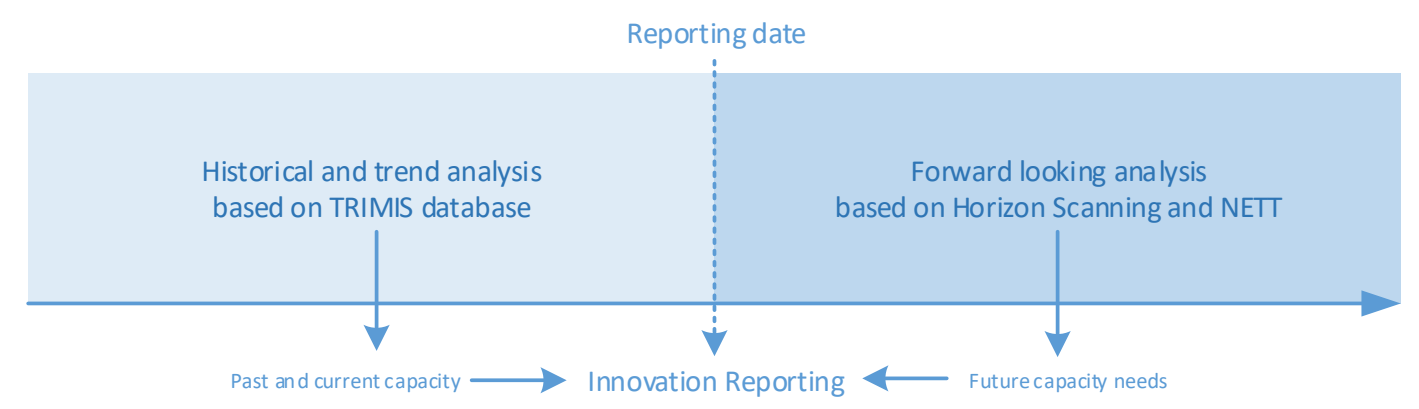

Figure 3. TRIMIS bidirectional monitoring and assessment approach (Composed by the authors).

The core element of TRIMIS is its database. Since its launch, the TRIMIS database evolved from a single table with project and program information into a relational database that incorporates information on several transport R\&I dimensions [44]. Figure 4 presents the TRIMIS database structure, highlighting four different fields (A, B, C, D) with eight different tables (project table, program table, technology table, organization table, labor statistics table, economic statistics table, patent table, horizon scanning table). The database structure provides an insight into TRIMIS' current and future analytical capabilities.

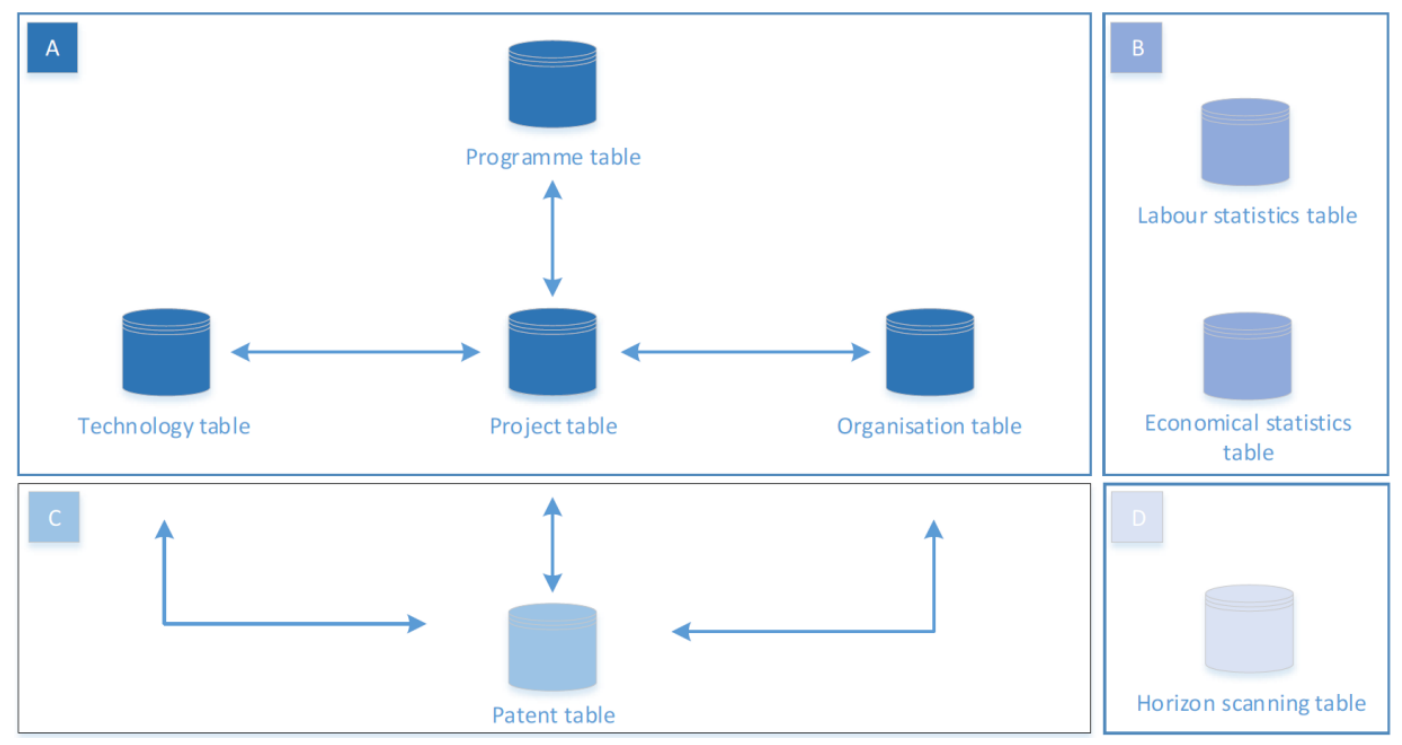

Figure 4. TRIMIS database structure (A) Main tables; (B) Additional data tables; (C) Patent data table; (D) Horizon scanning table [44]. 
Field A covers the main tables with information on transport innovation projects and programs, organizations and the technologies that are being developed. Field B includes several additional data tables created for ad-hoc macro-level innovation assessment that contain information on employment, public and private R\&I expenditure, and other socio-economic country statistics [45]. Field C contains patent data from PATSTAT, a worldwide patent statistical database created and maintained by the European Patent Office, with the aim to link patent information to the projects, technologies and organization tables. Finally, field D contains all information that is gathered in the framework of the horizon scanning process, which aims to forecast developments that shall shape transport R\&I.

Building on the TRIMIS database, it is possible to carry out both historical and trend analysis and forward-oriented innovation monitoring.

\subsection{Trend Analysis and Backward-Looking Elements}

The first aspect of TRIMIS is the historical and trend analysis of transport R\&I that allows it to communicate the status, progress and policy challenges to transport policymakers and stakeholders. To support this functionality, a comprehensive database containing information related to transport R\&I has been set up and is one of the core features of TRIMIS, as described above. A wide range of data relevant to transport R\&I are being collected, collated and added to the database using both crowdsourced user inputs and automated links to existing repositories. The database is further enriched by data from other European or external sources containing data with potential impact on transport R\&I (e.g., the European Patent Office). Thus, the database also includes data and indicators on transport technologies and innovations (i.e., projects, organizations, technologies).

Focusing specifically on the technologies database, a large effort has been made to assess the majority of European projects after 2007 for what regards the technologies they researched. Figure 5 provides an overview of the process, as presented in [46].
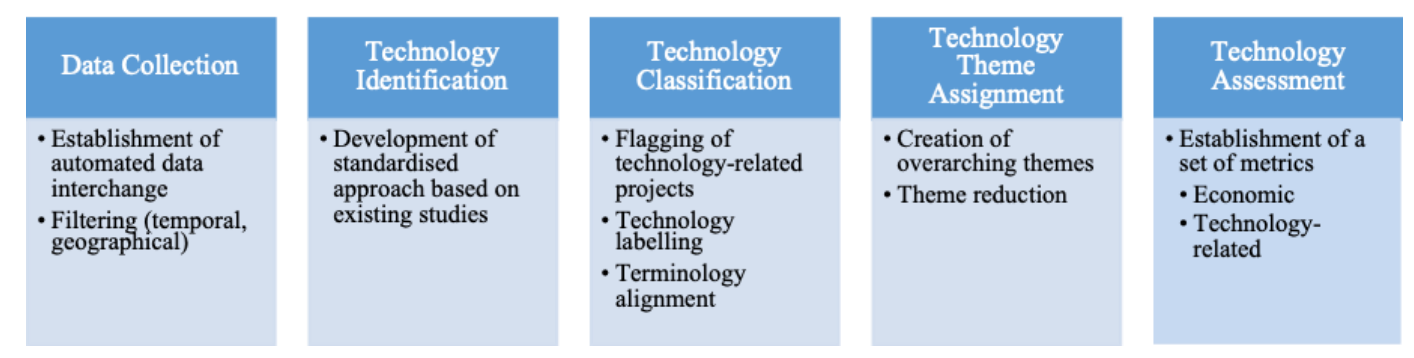

Figure 5. Methodological steps for the technology assessment (Adapted from [46]).

At the same time, the contents of the database constitute inputs for the development and use of a set of Key Performance Indicators (KPIs) that are necessary for the systematized and successful monitoring and assessment of transport R\&I. Another feature of TRIMIS is to monitor and assess the technical, financial and socio-economic capacities and performance of R\&I in the transport sector using a set of KPIs for each STRIA roadmap, thus undertaking the progress monitoring of EU and Member State-funded R\&I projects and programs further supporting the assessment of the transport sector R\&I performance and maturity status.

\subsection{Horizon Scanning, NETT and Forward-Looking Elements}

The second aspect of TRIMIS is the introduction of a forward-oriented approach in innovation monitoring through the use of strategic foresight and the development of an inventory on NETT in the transport sector [47].

To this aim, Horizon Scanning is used for identifying weak signals that facilitate the identification of promising technologies with a potential impact on the evolution of the transport sector and to promote the adoption of a forward-oriented culture in transport policymaking and governance. 
The identification of new technologies and opportunities that may have an impact on the transport sector and the flagging of mature technologies that are close to market introduction through an inventory of NETT relevant to the future of the EU transport sector are of crucial importance for TRIMIS. An overview of this process is presented in Figure 6.

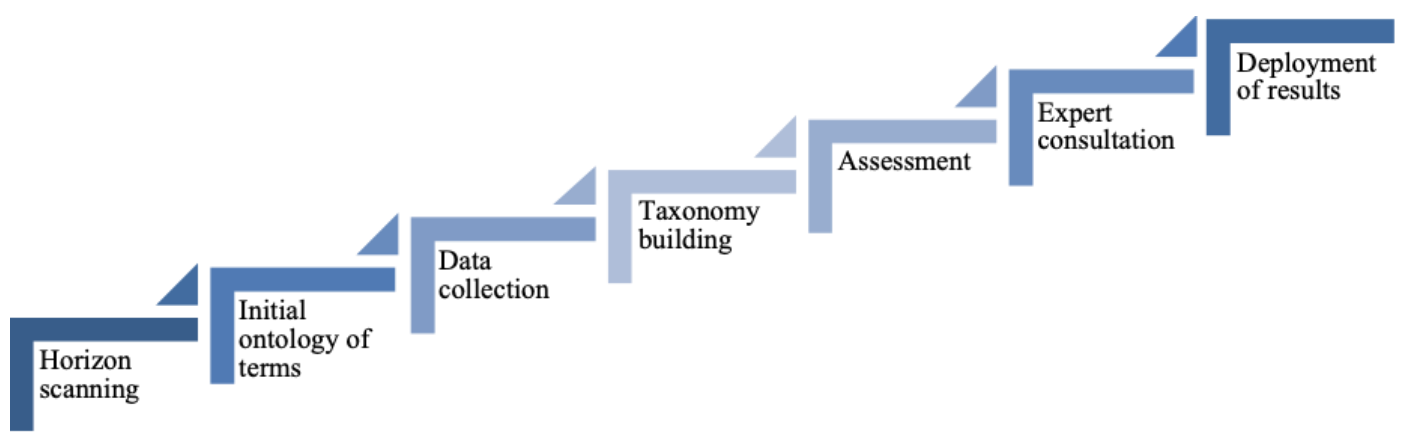

Figure 6. Steps towards creating an inventory of new and emerging technologies (Adapted from [48]).

The NETT inventory will be updated on an annual basis according to the updates occurring in the data sources identified in the methodology. All relevant technologies and trends will be organized and allocated to different categories, with the main categories, among others, being:

- New or innovative transport modes or large-scale technologies;

- New or innovative technologies with influence on existing transport practice.

The adoption of an appropriate tagging system allows the monitoring of relevance to different transport aspects, such as:

- Links to transport modes;

- The influence on the population or specific subcategories;

- The spatial reference;

- The technology maturity phase etc.

An assessment further supports the estimation of the potential impact of each technology based on expert judgement, not only based on strict socio-economic models but also on additional theories e.g., the Theory of Planned Behavior by Ajzen [49].

\subsection{Connection between STRIA and TRIMIS}

As was indicated above, STRIA and TRIMIS are distinct but inseparable parts. Figure 7 below can exemplify their respective roles and interaction. Building on the principles of better regulation and good governance [50], STRIA is primarily responsible for determining the needs and setting the objectives of what needs to be achieved in Europe's transport innovation system. TRIMIS, on the other hand, provides monitoring and evaluation support to understand which inputs and activities have been conducted, and to assess their effects. As such, TRIMIS is in a good position to assess the effectiveness and efficiency of research efforts.

In addition, through these analyses and accumulated knowledge, TRIMIS also provides feedback to the STRIA working groups on what potential future research needs are. TRIMIS therefore acts both as an evaluator and, to some extent, as an advisor to the benefit of the STRIA process.

Figure 7 shows the roles of the two parts in detail. STRIA does not introduce any legislation and therefore does not mandate any inputs or activities. It therefore is primarily responsible for identifying the transport sector's R\&I needs and to set objectives that need to be achieved under the various roadmaps. TRIMIS, consequently, monitors for each roadmap the inputs, activities, outputs, and outcomes so that it can be determined to which extent the STRIA objectives are achieved. 


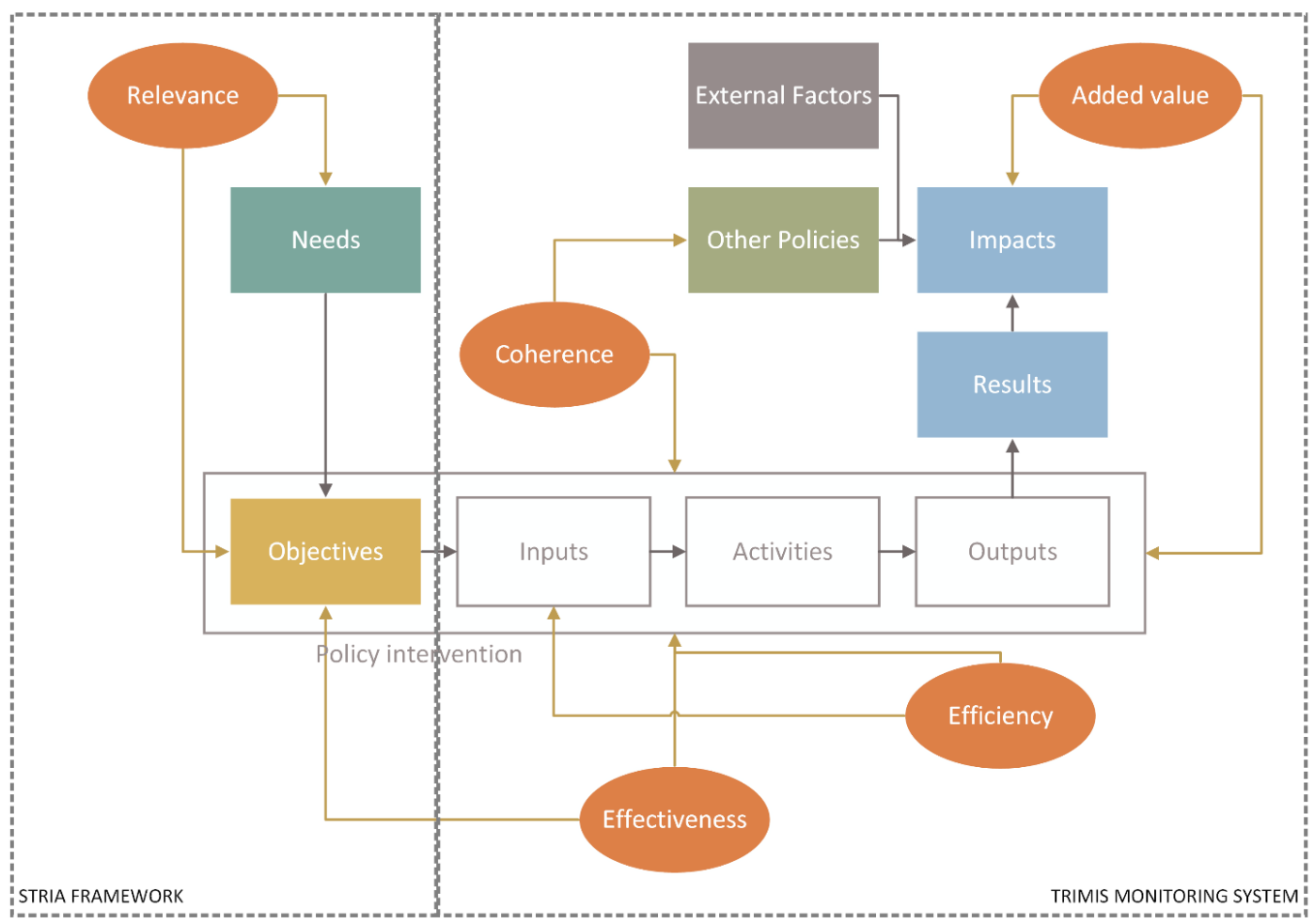

Figure 7. Intervention logic and the position of STRIA and TRIMIS (Adapted from [50]).

The link between the two parts is most evident in the roadmap monitoring exercise. On an annual basis, the STRIA working groups in the seven fields of transport technology are informed by TRIMIS on the extent to which roadmap targets are reached and, if not, what their expected timeline is. By doing so, TRIMIS provides current information on the status of each roadmap.

The roadmap assessment reports aid the STRIA working groups to reflect on the targets that they set. It can lead to objectives being revised, a shift in focus, or the introduction of new targets. Another impact can be that the STRIA working groups will make a case for a reallocation of resources in the field of transport R\&I, considering the fields that lag behind and those that excel. Such could lead to a change in inputs, the impact of which will again be monitored by TRIMIS.

The previous sections described the policy and monitoring system that has been put in place to assess transport innovation. The system has been developed in line with principles on good governance and better regulation. The system specifically allows us to assess the efficiency, effectiveness and coherence of research efforts in seven strategic fields of transport innovation. Whilst the system is developing further, a first glance is given on its capabilities in the section below.

\section{Case Study: the Contribution of Transport Research and Innovation to the European Green Deal}

In this section, a case study based on its analytical features is presented in order to illustrate the current capabilities of TRIMIS. The examples are drawn from a recent analysis on the R\&I in two key STRIA roadmaps: transport electrification (ELT) including hydrogen and low-emission alternative energy for transport (ALT) [51]. These two roadmaps are directly linked to the European Green Deal, and in particular, R\&I on these roadmaps can contribute to breaking transport dependency on oil and to decarbonizing the transport sector.

The decarbonization of electricity generation will allow for cleaner electricity for electric vehicles (EVs), which in turn will be able to provide additional storage services to the grid, thus supporting further expansion of the use of renewable sources. The development of innovative energy storage solutions is a cornerstone towards a fully electrified transport system, integrated in a clean energy 
network and along with the deployment of an adequate network of publicly available recharging points, can speed up the electrification of road transport [52-54].

On the other hand, an increase of the alternative low-emission energy share in the transport sector entails both technical and environmental challenges. Further R\&I is required towards the development of a new generation of powertrains that will lead to a technology leap, allowing for optimal use of ALT, aiming at the decarbonization of the transport sector. In terms of energy production, R\&I is required towards novel low-emission alternative energies, utilizing the benefits of renewable and sustainable sources [51].

The analysis focuses on the investments that were made since 2009 through European framework programs for research and technological development. Figure 8 shows the growing amount of funds directed towards research on various fuel types. The figure shows the summed average daily spending, derived by dividing the project funds by the project's duration in days.

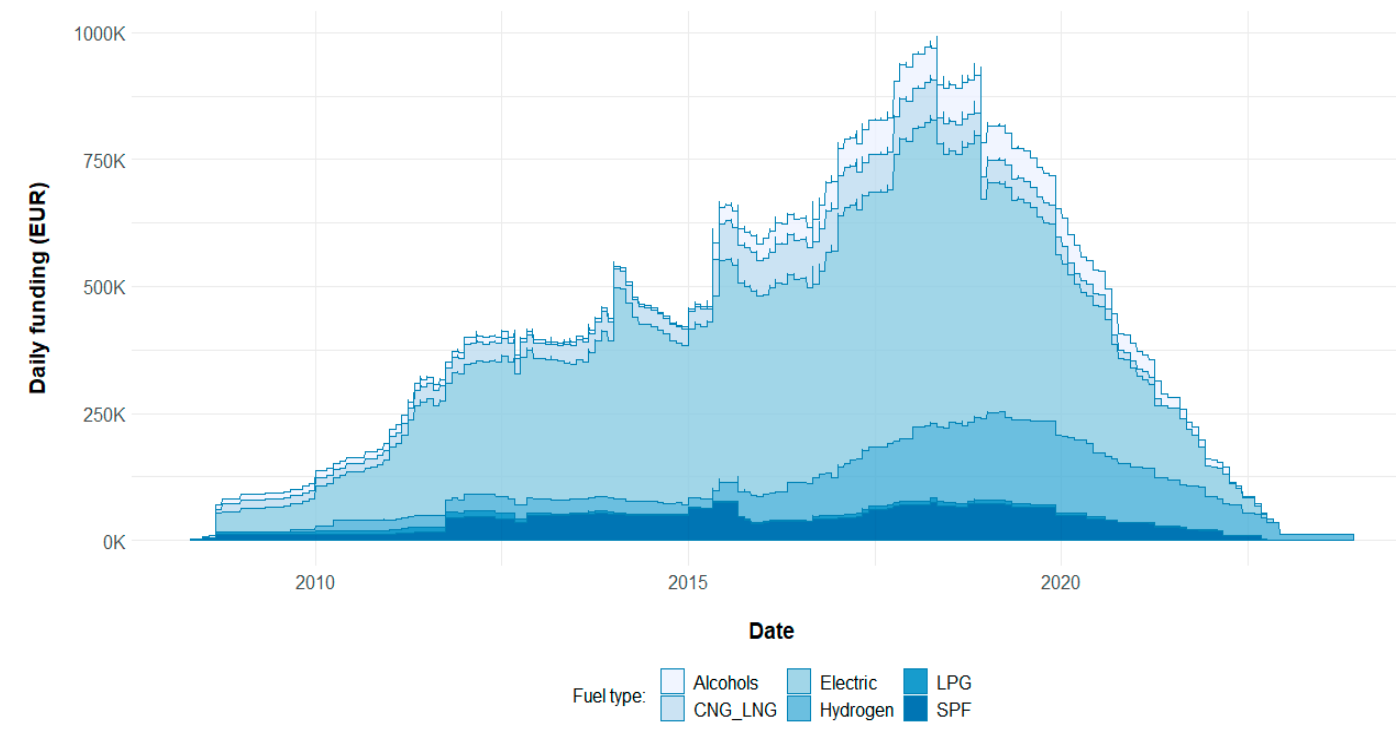

Figure 8. Funding for R\&I on fuel types through European framework programs (Composed by the authors).

Under the two most recent European framework programs for research and innovation (i.e., FP7 and H2020) an estimated EUR 3.6 bn has been invested in research projects related to transport electrification (EUR $2.8 \mathrm{bn}$, including hydrogen) and other alternative fuels (EUR $0.8 \mathrm{bn}$ ). The difference in the level of funding observed between these roadmaps explains the differences in the number of researched top technologies. Electric propulsion is clearly the largest category, with hydrogen receiving more funds since 2016. No significant evolution occurs concerning the funding of Synthetic Paraffinic Fuel (SPF) and Compressed Natural Gas (CNG)/ Liquefied Natural Gas (LNG) research. These findings, and the relative attribution of funds by type of fuel, could inform a study to assess if the funding differences are in line with policy priorities.

Figure 9 shows the geographical spread of the funding. Both the location of beneficiaries and the accumulated funds per region are provided. It is noted that most organizations that do research on different fuel types are located near the sites of major car and aviation manufacturers. It is equally visible that fewer beneficiary organizations are located in the east of Europe. Finally, a high level of similarity can be observed between the stakeholders and their geographic allocation in the fields of ELT and ALT. 


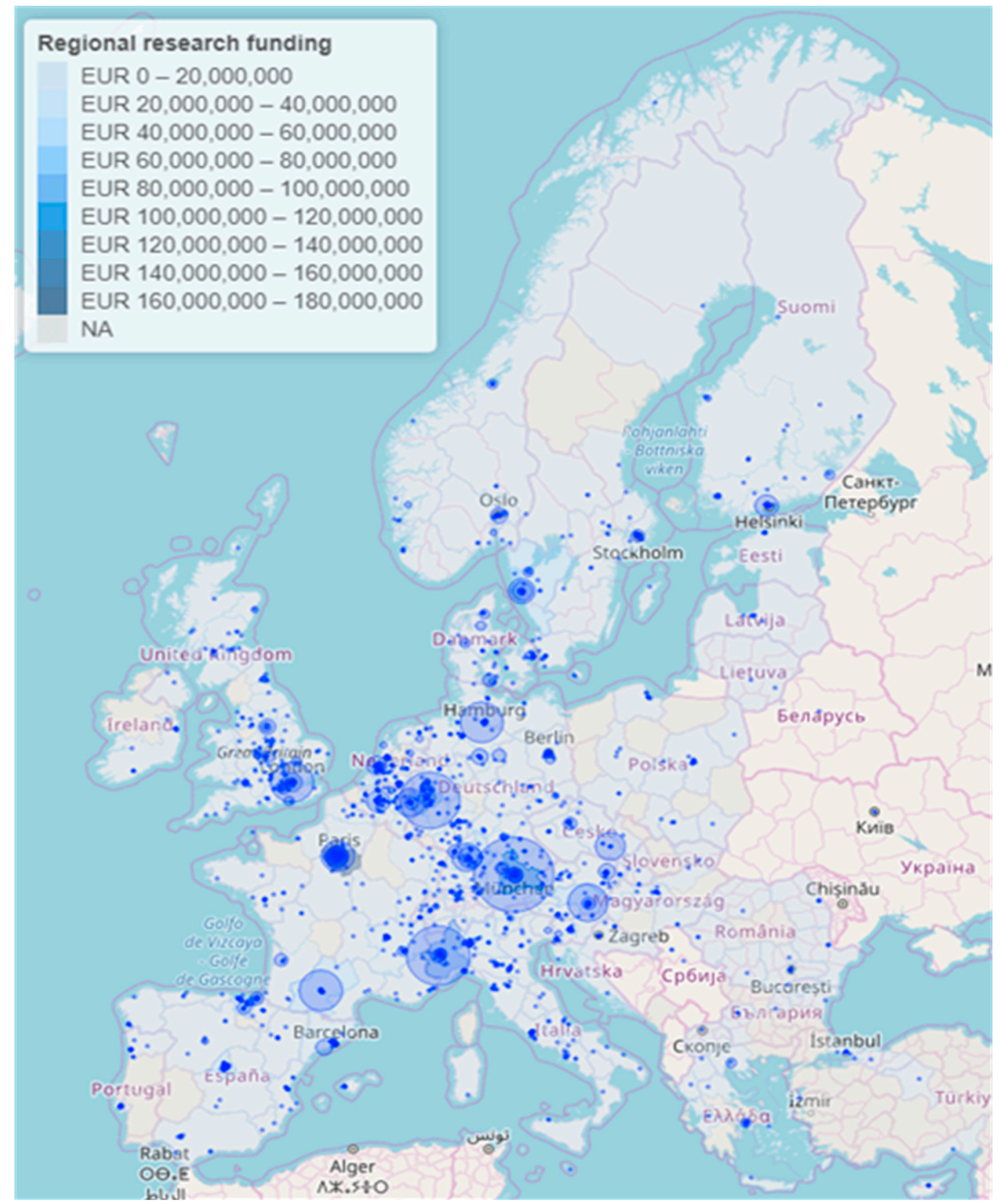

Figure 9. Geographic distribution ELT and ALT of R\&I organizations under Horizon 2020 (Composed by the authors).

Parallel to providing economic analyses, TRIMIS also focuses on the outcomes of transport technology innovation. Following the methodology described in Section 3, a total of 797 technologies were identified, researched within 2242 projects from FP7 and H2020 Framework Programs. 137 of the identified technologies are linked to the ELT roadmap, and 25 to the ALT roadmap. For each technology, several attributes are identified, with the principal ones being:

a. The number of projects that research the technology;

b. The total budget allocated for research in these projects;

c. The number of organizations that have been involved in projects that have researched the technology. 
The first two attributes highlight the combined effort that has been put into the technology, while the third one is an indication of the level of interest in the technology in industry and academia, indicating the available capabilities to bring the technology to market.

Figure 10 provides a snapshot of ELT and ALT technologies, focusing on the overall 'top $15^{\prime}$ technologies in terms of total investments identified for the two roadmaps. This kind of taxonomic representation of transport technologies implemented in TRIMIS allows to rapidly focus on different attributes.

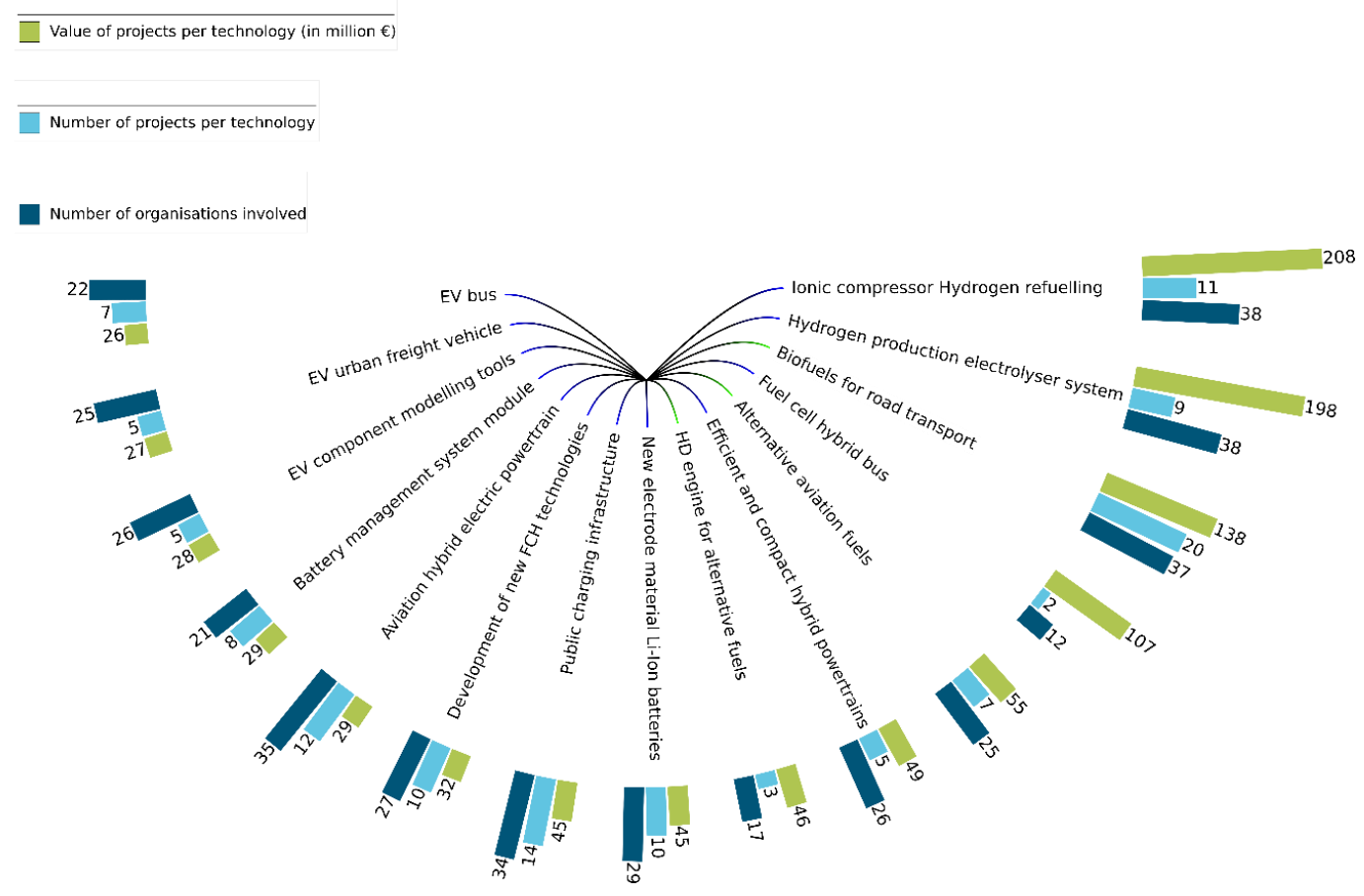

Figure 10. Top-15 ELT and ALT technologies in EU research Framework Programs (Composed by the authors); Bars not in scale. ELT: blue branches; ALT: green branches; Abbreviations: EV_Electric Vehicle; AF-Alternative Fuels; HD—Heavy Duty; FCH—Fuel Cells and Hydrogen.

By linking technology metrics with organizational data, technology value chains can be identified and assessed. This information can contribute to the optimization of funding programs and the development of targeted measures to promote the decarbonization of electricity generation and increase the alternative low-emission energy share in the transport sector.

These examples act as backward-looking analyses on the state of art in one field of transport research and are integrated with analyses on the impact on the development of new technologies (as expressed in patent publications) and their implementation (by mapping demonstrator projects). In addition, TRIMIS builds on the horizon scanning and NETT analysis to determine what the future trends are and if the research field, as it is, is able to cope with these challenges. Specifically, TRIMIS assesses whether the targets as defined in the STRIA roadmaps for ELT and ALT are met based on several inputs, including those mentioned above.

These reports are communicated directly with the STRIA working groups, which are responsible for the evaluation and revision of the roadmaps. As such, there is a direct feedback loop between the monitoring and policy parts of the transport innovation system.

\section{Discussion}

Despite the clear merits of the system, there are several risks and limitations that will be addressed in this section. Three points are identified to be most salient, namely (a) the data quality and the 
effectiveness of monitoring through TRIMIS, (b) the alignment between TRIMIS and STRIA, and (c) the impact of the system on actual transport research.

In relation to monitoring and data quality, a main issue remains to gather information on ongoing and announced research projects. TRIMIS makes this exercise manageable by focusing primarily on Europe and publicly funded projects, by establishing data interchanges with other research databases and by leveraging established contacts with research organizations. Nevertheless, the coverage and completeness of the database remains difficult to assess. Another issue related to data quality concerns the type of information that is collected. While it is relatively straightforward to measure inputs, activities and even outputs, it is considerably more difficult to assess the results and impacts of transport research. To address this point, TRIMIS is expanding its analytical capabilities to cover more data sources, including information on patents and firm performance. Still it is acknowledged that this will remain a challenging aspect of the monitoring role of TRIMIS.

The second main concern regards the feedback loop between TRIMIS and STRIA, which can be challenging in several ways. For example, STRIA can set objectives and targets that are hard, if not impossible to monitor through TRIMIS. Setting ambitious and abstract goals for transport research may seem appropriate but can greatly inhibit monitoring activities. It is therefore important that the objectives are defined in a specific, measurable, attainable, realistic and time bound (SMART) manner. The absence of objectives that pertain to these SMART criteria limits the relevance of both STRIA and TRIMIS. In addition, the feedback loop between TRIMIS and STRIA should be sufficiently frequent, so that monitoring insights can indeed be effectively integrated in a revision of the roadmaps. These operational concerns are of great importance and are currently addressed through several initiatives.

The final concern regards the impact of the system on actual transport research practices. STRIA and TRIMIS have no direct impact on the allocation of research funding or research activities. The system is therefore dependent on a wide number of stakeholders to embrace and act upon its findings. In order to do so, networks with the transport research community need to be maintained and the results of the roadmap monitoring exercises should be shared and explained to a broad audience. This is and remains a point of attention to align research efforts and truly catalyze innovation.

\section{Conclusions}

This paper reflected on the ways in which political decisions, innovation systems and tools support transport innovation to meet policy objectives, such as the reduction of transport emissions, in line with the objectives set out in the European Green Deal.

After a review of existing instruments, a gap was identified concerning the monitoring of research progress. The point was made that in order to catalyze transport research, an intertwined policy framework (STRIA) and monitoring system (TRIMIS) is valuable.

These two parts were explained in detail and the application of the system was exemplified through a case study on research on transport electrification and low emission alternative energy for transport.

From the analysis it can be seen that R\&I in these fields have been intensified both in terms of EU funding from framework programs for research and technological development, but also in terms of absolute number of projects and actors involved in this domain. Nevertheless, despite the significant spending on transport-related R\&I, there is still room for measures that could further accelerate the market uptake of new technologies and alternative fuels.

Transport electrification has the potential to play a key role towards a decarbonized transport system in the long-term. Nevertheless, the development of alternative vehicle powertrain technologies and an increased uptake of renewable energy sources will be also necessary to support the decarbonization process. In this context, it would be vital to increase the use of renewable energy sources and improve the overall transport system efficiency in the short- and medium-term.

More efforts are needed to deploy innovative technologies that reduce overall transport emissions and induce systemic changes. These efforts can help speed up the transition to low carbon/zero 
emission transport and are crucial to meet EU carbon reduction targets, in line with the objectives of the European Green Deal.

TRIMIS supports this transition by identifying revolutionary and evolutionary technologies, their funding and associated policy initiatives. By linking these data, it can be seen whether for revolutionary technologies, 'revolutionary support measures' are put in place and alternatively, if revolutionary technologies receive evolutionary support. By doing so, the anticipated transport revolution can be better monitored, evaluated and shaped.

Author Contributions: Conceptualization, A.T.; methodology, A.T.; software, M.v.B. and K.G.; validation, A.T. and F.P.; formal analysis, A.T., M.v.B. and K.G.; investigation, A.T., M.v.B. and K.G.; resources, A.T., M.v.B. and K.G.; data curation, M.v.B. and K.G.; writing—original draft preparation, A.T., M.v.B. and K.G.; writing-review and editing, A.T. and F.P.; visualization, A.T., M.v.B. and K.G.; supervision, F.P.; project administration, F.P.; funding acquisition, F.P. All authors have read and agreed to the published version of the manuscript.

Funding: This research received no external funding.

Acknowledgments: The views expressed here are purely those of the authors and may not, under any circumstances, be regarded as an official position of the European Commission. The Joint Research Centre is in charge of the development of TRIMIS, and the work has been carried out under the supervision of the Directorate-General for Mobility and Transport (DG MOVE) and the Directorate-General for Research and Innovation (DG RTD) that are co-leading the Strategic Transport Research and Innovation Agenda (STRIA).

Conflicts of Interest: The authors declare no conflict of interest.

\section{Glossary}

$\mathrm{AF}$

ALT

CNG

DG MOVE

DG RTD

EC

ELT

EU

EV

$\mathrm{FCH}$

FP7

H2020

HD

ICT

JRC

KPI

LNG

LPG

NETT

R\&I

SET

SMART

SME

SPF

STRIA

SUMP

TRID

TRIMIS
Alternative Fuel

Low-emission Alternative Energy for Transport

Compressed Natural Gas

Directorate-General for Mobility and Transport

Directorate-General for Research and Innovation

European Commission

Transport Electrification

European Union

Electric Vehicle

Fuel Cells and Hydrogen

7th Framework Program for Research

Horizon 2020 Framework Program for Research and Innovation

Heavy Duty

Information and Communication Technology

Joint Research Centre

Key Performance Indicator

Liquefied Natural Gas

Liquefied Petroleum Gas

New and Emerging Transport Technologies and Trends

Research and Innovation

Strategic Energy Technology

Specific, Measurable, Attainable, Realistic and Time Bound

Small and Medium-Sized Enterprise

Synthetic Paraffinic Fuel

Strategic Transport Research and Innovation Agenda

Sustainable Urban Mobility Plan

Transport Research International Documentation

Transport Research and Innovation Monitoring and Information System 


\section{References}

1. Eurostat Final Energy Consumption by Sector. Available online: https://ec.europa.eu/eurostat/web/productsdatasets/-/ten00124 (accessed on 14 April 2020).

2. European Environment Agency Sectoral Greenhouse Gas Emissions by IPCC Sector. Available online: https: //www.eea.europa.eu/data-and-maps/daviz/change-of-co2-eq-emissions-2/\#parent-fieldname-title (accessed on 4 February 2020).

3. European Environment Agency. Annual European Union Greenhouse Gas Inventory 1990-2015 and Inventory Report 2017; European Environment Agency: Copenhagen, Denmark, 2017.

4. Giannopoulos, G.A. Publicly Funded Transport Research in the P.R. China, Japan, and Korea: Policies, Governance and Prospects for Cooperation with the outside World; Springer: Berlin, Germany, 2018; ISBN 978-3-319-68197-9. [CrossRef]

5. Auvinen, H.; Tuominen, A. Future transport systems: Long-term visions and socio-technical transitions. Eur. Transp. Res. Rev. 2014, 6, 343-354. [CrossRef]

6. Ménière, Y.; Rudyk, I.; Tsitsilonis, L. Patents and Self-Driving Vehicles, the Inventions Behind Automated Driving; European Patent Office: Munich, Germany, 2018; ISBN 978-3-89605-221-6.

7. Millar, C.; Lockett, M.; Ladd, T. Disruption: Technology, innovation and society. Technol. Forecast. Soc. Chang. 2018, 129, 254-260. [CrossRef]

8. Hyard, A. Non-technological innovations for sustainable transport. Technol. Forecast. Soc. Chang. 2013, 80, 1375-1386. [CrossRef]

9. Wasiak, M.; Jacyna, M.; Lewczuk, K.; Szczepański, E. The Method for Evaluation of Efficiency of the Concept of Centrally Managed Distribution in Cities. Transport 2017, 32, 348-357. [CrossRef]

10. Jacyna-Gołda, I.; Gołębiowski, P.; Izdebski, M.; Kłodawski, M.; Jachimowski, R.; Szczepański, E. The evaluation of the sustainable transport system development with the scenario analyses procedure. J. Vibroeng. 2017, 19, 5627-5638. [CrossRef]

11. Giannopoulos, G.A.; Munro, J.F. The Accelerating Transport Innovation Revolution, 1st ed.; Elsevier: Amsterdam, The Netherlands, 2019; ISBN 978-0-12-813804-5.

12. Cascetta, E. Transportation Systems Engineering: Theory and Methods; Springer: Berlin, Germany, 2001; ISBN 978-1-4757-6873-2. [CrossRef]

13. Heiskanen, E.; Hyvönen, K.; Niva, M.; Pantzar, M.; Timonen, P.; Varjonen, J. User involvement in radical innovation: Are consumers conservative? Eur. J. Innov. Manag. 2007, 10, 489-509. [CrossRef]

14. Bonvillian, W.B.; Weiss, C. Technological Innovation in Legacy Sectors; Oxford University Press: New York, NY, USA, 2015; ISBN 978-0-19-937451-9. [CrossRef]

15. Axsen, J.; Kurani, K.S. Interpersonal Influence within Car Buyers' Social Networks: Applying Five Perspectives to Plug-in Hybrid Vehicle Drivers. Environ. Plan. A 2012, 44, 1047-1065. [CrossRef]

16. Dedehayir, O.; Steinert, M. The hype cycle model: A review and future directions. Technol. Forecast. Soc. Chang. 2016, 108, 28-41. [CrossRef]

17. Wilenius, M.; Casti, J. Seizing the X-events. The sixth K-wave and the shocks that may upend it. Technol. Forecast. Soc. Chang. 2015, 94, 335-349. [CrossRef]

18. Van Zuylen, H.J.; Weber, K.M. Strategies for European innovation policy in the transport field. Technol. Forecast. Soc. Chang. 2002, 69, 929-951. [CrossRef]

19. Jacyna, M.; Wasiak, M.; Lewczuk, K.; Karoń, G. Noise and environmental pollution from transport: Decisive problems in developing ecologically efficient transport systems. J. Vibroeng. 2017, 19, 5639-5655. [CrossRef]

20. Jacyna, M.; Merkisz, J. Proecological Approach to Modelling Traffic Organization in National Transport System. Arch. Transp. 2014, 30, 31-41. [CrossRef]

21. European Commission. The European Green Deal COM/2019/640 Final; European Commission: Brussels, Belgium, 2019.

22. Contag, M.; Li, G.; Pawlowski, A.; Domke, F.; Levchenko, K.; Holz, T.; Savage, S. How They Did It: An Analysis of Emission Defeat Devices in Modern Automobiles. In Proceedings of the 2017 IEEE Symposium on Security and Privacy (SP), San José, CA, USA, 22-26 May 2017; pp. 231-250. [CrossRef]

23. Rowley, T.J. Moving beyond dyadic ties: A network theory of stakeholder influences. Acad. Manag. Rev. 1997, 22, 887-910. [CrossRef] 
24. Freeman, R.E. Strategic Management: A Stakeholder Approach; Pitman Publishing: Boston, MA, USA, 1984.

25. Oum, T.H.; Adler, N.; Yu, C. Privatization, corporatization, ownership forms and their effects on the performance of the world's major airports. J. Air Transp. Manag. 2006, 12, 109-121. [CrossRef]

26. Van der Lugt, L.; Dooms, M.; Parola, F. Strategy making by hybrid organizations: The case of the port authority. Res. Transp. Bus. Manag. 2013, 8, 103-113. [CrossRef]

27. Morgan, S. 'Disappointed' EU Capitals Agree on 35\% Car $\mathrm{CO}_{2}$ Cuts. Available online: https://www.euractiv. $\mathrm{com} /$ section/transport/news/disappointed-eu-capitals-agree-on-car-co2-cuts/ (accessed on 25 May 2019).

28. Porter, M. How Competitive Forces Shape Strategy. Harv. Bus. Rev. 1979, 57, 137-145. [CrossRef]

29. WIPO World Intellectual Property Indicators 2018; World Intellectual Property Organization: Geneva, Switzerland, 2018; ISBN 978-92-805-2984-5.

30. Wiesenthal, T.; Condeço-Melhorado, A.; Leduc, G. Innovation in the European transport sector: A review. Transp. Policy 2015, 42, 86-93. [CrossRef]

31. Jacyna, M.; Wasiak, M. Multicriteria Decision Support in Designing Transport Systems. In Tools of Transport Telematics. TST 2015. Communications in Computer and Information Science; Mikulski, J., Ed.; Springer: Berlin, Germany, 2015; Volume 531, pp. 11-23. ISBN 978-3-319-24577-5.

32. Etzkowitz, H.; Leydesdorff, L. The dynamics of innovation: From National Systems and "Mode 2" to a Triple Helix of university-industry-government relations. Res. Policy 2000, 29, 109-123. [CrossRef]

33. Hekkert, M.P.; Suurs, R.A.A.; Negro, S.O.; Kuhlmann, S.; Smits, R.E.H.M. Functions of innovation systems: A new approach for analysing technological change. Technol. Forecast. Soc. Chang. 2007, 74, 413-432. [CrossRef]

34. European Commission. Public-Private Partnerships in Horizon 2020: A Powerful Tool to Deliver on Innovation and Growth in Europe, COM(2013) 494 Final; European Commission: Brussels, Belgium, 2013.

35. European Commission Developing Horizon Europe. Available online: https://ec.europa.eu/info/horizoneurope-next-research-and-innovation-framework-programme_en (accessed on 4 February 2020).

36. European Commission. A European Strategy for Low-Emission Mobility COM/2016/0501 Final; European Commission: Brussels, Belgium, 2016.

37. European Commission. Accelerating Clean Energy Innovation COM/2016/0763 Final; European Commission: Brussels, Belgium, 2016.

38. European Commission. Energy Union Package-A Framework Strategy for a Resilient Energy Union with a Forward-Looking Climate Change Policy COM/2015/080 Final; European Commission: Brussels, Belgium, 2015.

39. European Commission. Towards Clean, Competitive and Connected Mobility: The Contribution of Transport Research and Innovation to the Mobility Package SWD/2017/0223 Final; European Commission: Brussels, Belgium, 2017.

40. European Commission. Towards an Integrated Strategic Energy Technology (SET) Plan: Accelerating the European Energy System Transformation C/2015/6317 Final; European Commission: Brussels, Belgium, 2015.

41. Tsakalidis, A.; Gkoumas, K.; Pekar, F.; Grosso, M.; Haq, G.; Marelli, L. Towards an integrated European platform for monitoring and analysing transport research and innovation (TRIMIS). In Proceedings of the 7th Transport Research Arena TRA 2018, Vienna, Austria, 16-19 April 2018. [CrossRef]

42. Tsakalidis, A.; van Balen, M.; Gkoumas, K.; Grosso, M.; Haq, G.; Pekar, F. Towards an Integrated Monitoring and Assessment Framework for the Strategic Transport Research and Innovation Agenda-Using TRIMIS as a Policy Support Mechanism; Publications Office of the European Union: Luxembourg, 2018; ISBN 978-92-79-92583-2. [CrossRef]

43. Habegger, B. Horizon Scanning in Government; Centre for Security Studies: Zurich, Switzerland, 2009.

44. Van Balen, M.; Ortega Hortelano, A.; Grosso, M.; Tsakalidis, A.; Gkoumas, K.; Haq, G.; Pekar, F. EU Transport Research E Innovation Status Assessment Report: An Overview Based on the Transport Research and Innovation Monitoring and Information System (TRIMIS) Database; Publications Office of the European Union: Luxembourg, 2019; ISBN 978-92-76-09005-2. [CrossRef]

45. Grosso, M.; van Balen, M.; Ortega Hortelano, A.; Haq, G.; Gkoumas, K.; Tsakalidis, A.; Pekár, F. Innovation Capacity of the European Transport Sector, A Macro-Level Analysis; Publications Office of the European Union: Luxembourg, 2019; ISBN 978-92-76-03655-5. [CrossRef]

46. Gkoumas, K.; van Balen, M.; Ortega Hortelano, A.; Tsakalidis, A.; Grosso, M.; Haq, G.; Pekar, F. Research and Innovation in Transport Infrastructure in Europe: An Assessment Based on the Transport Research and Innovation Monitoring and Information System (TRIMIS); Publications Office of the European Union: Luxembourg, 2019; ISBN 978-92-76-09539-2. [CrossRef] 
47. Gkoumas, K.; Tsakalidis, A. A Framework for the Taxonomy and Assessment of New and Emerging Transport Technologies and Trends. Transport 2019, 34, 455-466. [CrossRef]

48. Gkoumas, K.; Tsakalidis, A.; van Balen, M.; Grosso, M.; Haq, G.; Ortega Hortelano, A.; Pekar, F. Inventory, Modelling and Assessment of New and Emerging Technologies and Trends (NETT) in the Transport Sector: A Methodology for the Transport Research and Innovation Monitoring and Information System (TRIMIS); Publications Office of the European Union: Luxembourg, 2018; ISBN 978-92-79-97224-9. [CrossRef]

49. Ajzen, I. From Intentions to Actions: A Theory of Planned Behavior. In Action Control; Springer: Berlin, Germany, 1985; pp. 11-39. [CrossRef]

50. European Commission. Better Regulation for Better Results-An EU Agenda COM/2015/0215 Final; European Commission: Brussels, Belgium, 2015.

51. Ortega Hortelano, A.; van Balen, M.; Gkoumas, K.; Haq, G.; Tsakalidis, A.; Grosso, M.; Pekár, F. Research and Innovation in Low Emission Alternative Energy for Transport; Publications Office of the European Union: Luxembourg, 2019; ISBN 978-92-76-12601-0. [CrossRef]

52. Thiel, C.; Tsakalidis, A.; Jäger-Waldau, A. Will Electric Vehicles Be Killed (again) or Are They the Next Mobility Killer App? Energies 2020, 13, 1828. [CrossRef]

53. Tsakalidis, A.; Julea, A.; Thiel, C. The Role of Infrastructure for Electric Passenger Car Uptake in Europe. Energies 2019, 12, 4348. [CrossRef]

54. Tsakalidis, A.; Thiel, C. Electric vehicles in Europe from 2010 to 2017: Is Full-Scale Commercialisation Beginning? Publications Office of the European Union: Luxembourg, 2018; ISBN 978-92-79-96719-1. [CrossRef]

(C) 2020 by the authors. Licensee MDPI, Basel, Switzerland. This article is an open access article distributed under the terms and conditions of the Creative Commons Attribution (CC BY) license (http://creativecommons.org/licenses/by/4.0/). 